DOI: https://doi.org/10.24867/02AM02Aleksic

\title{
OPTIMIZACIJA PARAMETARA PROCESA REZANJA POMOĆU PRIRODOM INSPIRISANIH ALGORITAMA
}

\section{OPTIMIZATION OF CUTTING PARAMETERS BY NATURE-INSPIRED ALGORITHMS}

\author{
Anđelko Aleksić, Milenko Sekulić, Fakultet tehničkih nauka, Novi Sad
}

\begin{abstract}
Oblast - MAŠINSTVO
Kratak sadržaj - U radu je prikazan kratak osvrt na značaj modelovanja procesa obrade kao i osnovne metode modelovanja. Dat je teoretski deo o optimizaciji procesa obrade sa kratkim pregledom metoda optimizacije, kao što su: lokalno pretraživanje, algoritam simultanog žarenja $i$ algoritam slepog miša. Detaljno je opisan mravlji algoritam - ACO i algoritam roja čestica - PSO. Prikazana su eksperimentalna istraživanja i matematički model na osnovu kog je vršena optimizacija pomoću ACO, PSO i GA (genetski algoritam). Takođe je izvršeno poređenje rezultata dobijenih optimizacijom pomoću prirodominspirisanih algoritama (ACO, PSO $i$ GA) sa jednom klasičnom optimizacionom metodom, Taguči metod. Na kraju rada dat je prilog $u$ kome su predstavljeni print skrinovi korisničkog interfejsa programa MATLAB, pri optimizaciji pomoću ACO, PSO i GA.
\end{abstract}

Ključne reči: Optimizacija, prirodom inspirisani algoritmi, mravlji algoritam, optimizacija rojem čestica.

Abstract - This paper gives a brief overview of the importance of modeling the processing process as well as the basic modeling model. There is a theoretical part about optimization methods, suc as: local search, simulated anneling and bat algorithm. Ant colony optimization i particle swarm optimization are described in detail. Experimental research and a mathematical model based on which ACO, PSO and GA (genetic algorithm) were performed were presented. Comparison of the reults obrained by optimization with the natureinspired algorithms (ACO, PSO and GA) was also compared with a classical optimization method Taguchi method. At the end of the work, there is an attachment in which the prin screens of the MATLAB user interface are presented, with ACO, PSO and GA optimization.

Keywords: Optimization, nature-inspired algorithm, ant colony optimization, particle swarm optimization

\section{UVOD}

Predmet istraživanja rada predstavlja istraživanje na polju prirodom inspirisanih metoda za optimizaciju procesa obrade rezanjem. Metode optimizacije na kojima su vršena istraživanja su: optimizacija pomoću mravljeg algoritma (eng. Ant Colony Optimization - ACO), optimizacija pomoću rojeva čestica (eng. Particle Swarm Optimization - PSO) i optimizacija pomoću genetskog algoritma (eng. Genetic Algorithm).

\section{NAPOMENA:}

Ovaj rad proistekao je iz master rada čiji mentor je bio dr Milenko Sekulić.
Cilj istraživanja jeste ispitivanje mogućnosti efikasne primene ovih metoda (algoritama) u optimizaciji procesa obrade rezanjem. Mogućnosti ovih optimizacionih algoritama su ispitane na primeru optimizacije procesa obrade čeonim glodanjem. Kao funkcija cilja je odabrana minimalna vrednost srednje aritmetičke hrapavosti $(R a) m i n-$ $[\mu m]$.

\section{MODELOVANJE PROCESA OBRADE REZANJEM}

Modelovanje procesa obrade predstavlja prvi neophodna korak za optimizaciju parametara procesa. Predstavlja razumevanje principa procesa obrade pomoću razvoja eksplicitnog matematičkog modela koji prezentuje realni sistem. Dakle, optimalni izbor parametara obrade je nezamisliv bez prethodnog definisanja pouzdanog matematičkog modela.

Svrha modelovanja procesa obrade je da se: realno predvide rezultati procesa, da se steknu nova znanja o pojedinim fazama procesa koja će pomoći projektovanju samog procesa, brzo i realno izvrši optimizacija procesa, izvedu zaključci o praćenju i upravljanju procesom.

U praksi se mogu sresti sledeće vrste modela: empirijski modeli, mehanistički modeli, analitički modeli, numerički modeli, modeli zasnovani na veštačkoj inteligenciji, modeli zasnovani na višefaktornom planu eksperimenta $\mathrm{i}$ hibridni modeli.

\section{METODE ZA OPTIMIZACIJU PROCESA OBRADE REZANJEM}

Optimizacija predstavlja postupak definisanja najpovoljnijih rešenja za date početne uslove, iz skupa mogućih rešenja. Objekat optimizacije može biti neki proces $u$ širem ili užem obliku ili sistem (tehnološki, obradni, proizvodno-pogonski ili neko drugo postrojenje, instalacija, proizvod, alat, itd.). Nema ograničenja kada je u pitanju izbor objekta optimizacije, jer postoji potreba da se svako tehničko ili tehnološko rešenje unapredi, što se itekako postiže primenom metoda optimizacije. Prema tome, nema tehničkih nauka niti inženjerskih problema, gde se manje ili više ne koriste metode optimizacije. Može se reći da gotovo ne postoji područje čovekove delatnosti, sistema ili procesa koji se na neki način ne bi mogao optimizovati.

Neka od opštih podela optimizacije jeste na: makrooptimizaciju (izbor optimalne varijante tehnološkog procesa) i mikrooptimizaciju (optimizacija rećžima obrade, geometrije alata, ...).

Za rešavanje problema optimizacije parametara procesa obrade koristi se širok spektar optimizacionih metoda i algoritama. U literaturi se mogu sresti različite podele 
ovih metoda i algoritama. Optimizacioni algoritmi se, po mišljenju nekih autora, mogu svrstati u dva različita tipa: Tradicionalni i netradicionalni algoritmi [5].

\section{MRAVLJI ALGORITAM}

Termin „Ant Colony Optimization (ACO) “ uvodi Marco Dorigo u svom doktoratu iz 1992. godine [1], kao rezultat istraživanja kombinatornih optimizacionih pristupa. U početku, algoritam se primenjivao na problem trgovačkog putnika i problem udruživanja kvadranta. Od 1995. Dorigo i ostali rade na raznim proširenim verzijama početne ideje.

Mravi imaju sposobnost da pronađu najkraću putanju koja vodi od mravinjaka do izvora hrane bez ubotrebe vizuelnog znaka. Ovu sposobnost mravi realizuju tako što svojim kretanjem po tlu ostavljaju određenu količinu hemijske supstance poznate kao feromon. Pored toga, poseduju mogućnost prilagođavanja novonastalim promenama oko njih. Na primer, kada nađu najkraći put do izvora hrane, u slučaju pojave neke barijere na putu ili zakrčenja puta, pronalaze novi najkraći put.

Jedan od prvih eksperimenata, u laboratorijskim uslovima, provere sposobnosti mrava da nađu najkraću putanju jeste „eksperiment sa dva mosta“. Vršeno je dva različita načina ispitivanja, prvi je predstavljao most sa jednakim dužinama grana, dok drugi eksperiment je izveden sa različitim dužinama grana mosta, prikazano na slici 4.1.

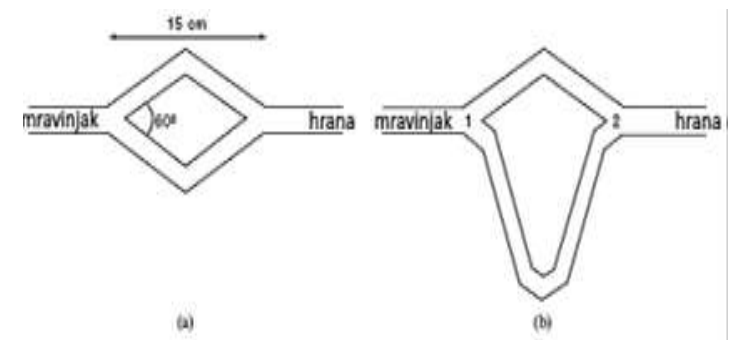

Slika 4.1: Postavke eksperimenta dvostrukog mosta: a) sa jednakim granama i b) sa različitim dužinama grana [1]

U prvom slučaju (pod a) mravinjak kolonije mrava povezan je sa izvorom hrane preko dva mosta jednake dužine. Duž putanje između izvora hrane i gnezda, mravi deponoju feromon. Inicijalno, tj. na početku eksperimenta, svaki mrav nasumično bira jedan od dva mosta (slika 4.1a). Međutim, kao posledica slučajnog protoka mrava, posle nekog vremena na jednom od dva mosta pojaviće se veća koncentracija feromona koja će kao posledicu privući više mrava.

Ovo dodatno povećava koncentraciju feromona na tom mostu, što ga čini privlačnijim za mave, a kao posledica toga nakon nekog vremena čitava kolonija će težiti da koristi isti most. Deneubourgh i njegovi saradnici su ponovili eksperiment više puta i zapazili da će mravi odabradi jedan od dva mosta sa verovatnoćom od $50 \%$. Ovakvo ponašanje na nivou kolonije, zasnovano na eksploataciji povratne informacije, mravi koriste kako bi pronašli najkraći put između izvora hrane i njihovog gnezda [1].

Goss i njegove kolege su razmatrali varijantu eksperimenta sa dva mosta u kojoj je jedan most značajno duži od drugog (slika 4.1b). U ovom slučaju stohastički protok kod inicijalnog odabira mosta je značajno redukovan, a drugi mehanizam igra značajnu ulogu. Naime, mravi koji slučajnim izborom odaberu kraći most, prvi će stići nazad do mravinjaka. Kraći most će stoga primiti feromon ranije nego duži, a ova činjenica povećava verovatnoću da će mravi koji slede, odabrati kraći most pre nego duži most. Goss i njegovi saradnici su razvili matematički model posmatranog ponašanja.

Mravi, iako su slepi, mogu naći najkraću putanju do izvora hrane. Ova karakteristika mrava je na raspolaganju za rešavanje stvarnih problema korišćenjem određenih karakteristika i nekih dodataka. Karakteristike mrava koje stvaraju veštačke mrave su: komunikacija između mrava pomoću hemijske supstance feromon, preferiranje puteva sa većom količinom feromona, brže povećanje feromona na kraćim putevima, nego na dužim.

Karakteristike koje su dodate stvarnim mravima: žive u okruženju gde se vreme obračunava diskretno, potpuno su slepi i mogu pristupiti detaljima o problemu, mogu zadržati informacije za rešavanje određenog problema sa određenom količinom memorije [1].

Način funkcionisanja algoritma prikazan je pseudokodom (algoritam 4.1).

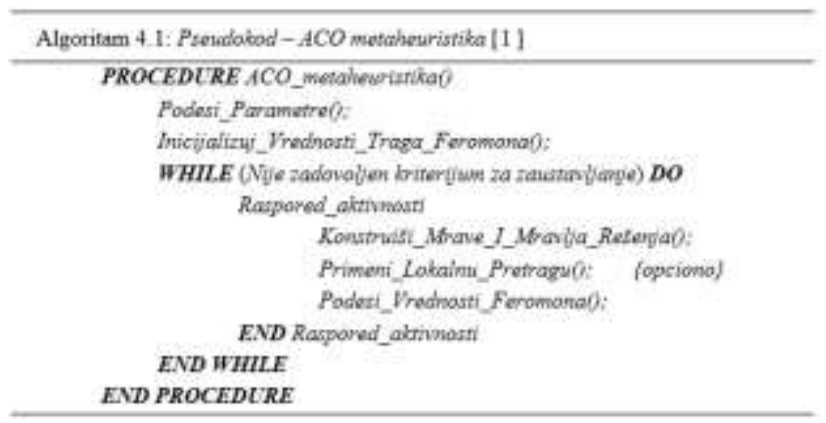

\section{OPTIMIZACIJA ROJEM ČESTICA - PSO}

Optimizacija rojem čestica (eng. Paricle Swarm Optimization - PSO) je stohastički algoritam koji se bazira na populaciji rešenja. Algoritam optimizacije rojem čestica otkriven je sasvim slučajno, pri pokušaju da se na računaru simulira kretanje jata ptica. Reynolds C.W. u svom radu 1986. godine razmatra jato ptica kao skup čestica gde svaka čestica (tj. ptica) svoj let prilgođava sledećim pravilima, što je takođe prikazano na slici 5.1:

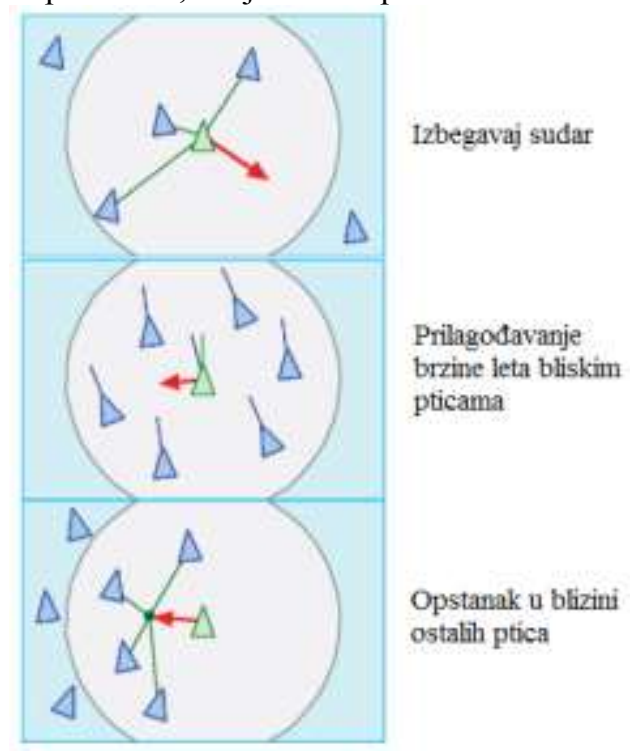

Slika 5.1: Način funkcionisanja jedinke u jatu [2] 
Sam algoritam je u određenoj meri inspirisan i sociološkim interakcijama između pojedinaca u populaciji. Svaka čestica je potencijalno rešenje razmatranog problema i koristi sopstveno iskustvo i iskustvo susednih čestica da bi odabrala kako da se kreće u prostoru pretrage. U fazi inicijalizacije svakoj čestici je dat slučajno odabrani položaj i početna brzina. Pozicija čestice predstavlja rešenje problema i zato ima vrednost datu funkcijom cilja. Dok se kreću u prostoru pretrage čestice pamte položaj, tj. poziciju najboljeg rešenja koje su našle. U svakoj iteraciji algoritma svaka četica se kreće brzinom koja je suma tri komponente: stare brzine, brzine koja pokreće česticu ka poziciji u prostoru pretrage gde je prethodno pronašla najbolje rešenje do tada $\mathrm{i}$ brzine koja pokreće česticu prema lokaciji u prostoru pretrage gde su susedne čestice našle najbolje rešenje do tada. PSO algoritam je primenjen na velikom broju različitih problema i još je jedan primer veštačko-inženjerskog SI sistema.

Roj čestica je u prirodi stohastičan, on iskorišćava vektor brzine kako bi ažurirao trenutnu poziciju svake čestice u roju. Vektor brzine se ažurira na temelju pamćenja svake čestice, što koncepcijski odgovara autobiografskoj memoriji, kao i na temelju znanja koje je stekao roj kao celina. Pozicija čestice u jatu je ažurirana na temelju socijalnog ponašanja roja koji se prilagođava svom okruženju stalnim traženjem boljih pozicija tokom vremena.

Numerički, pozicija $x$ čestice $i$ u iteraciji $k+1$ je ažurirana na sledeći način:

$$
x_{k+1}^{i}=x_{k}^{i}+v_{k+1}^{i} \Delta t
$$

pri čemu je $v_{k+1}^{i}$ pripradajući ažurirani vector brzine, a $\Delta t$ je vrednost vremenske step funkcije. Vektro brzine svake čestice se računa kao:

$$
v_{k+1}^{i}=\omega v_{k}^{i}+c_{1} r_{1} \frac{\left(p_{k}^{i}-x_{k}^{i}\right)}{\Delta t}+c_{2} r_{2} \frac{\left(p_{k}^{g}-x_{k}^{i}\right)}{\Delta t}
$$

pri čemu je $v_{k}^{i}$ vektor brzine u iteraciji $k, p_{k}^{i}$ i $p_{k}^{g}$ predstavljaju najbolju poziciju čestice ikad i globalnu najbolju poziciju čitavog roja sve do trenutne iteracije $k$, dok $r$ predstavlja nasumični broj iz intervala $[0,1]$. Preostali članovi su konfiguracijski parametri koji igraju važnu ulogu u konvergencijskom ponašanju PSO-a. Član $c_{1}$ (kognitivni, samospoznajni parameter) predstavlja stepen poverenja u globalnom najboljem rešenju (najbolje pronađeno rešenje od jata kao celine). Uglavnom se uzima $1,8<c_{1}=c_{2}<2,2$. Poslednji član $\omega$ je iteracijska varijabla koja je iskorišćena za kontrolisanje istraživačkih sposobnosti roja tako da skalira vrednost trenutne brzine, te na taj način utiče na iznos ažuriranog vektora brzine. Većim vrednostima interacijske varijable ( $\omega)$ vršimo globalno pretraživanje zbog toga što se ažurirani vektor brzine brže povećava dok zadavanjem manje vrednosti inercijske varijable vrednost ažuriranog vektora brztine postaje manja pa se tako novi položaj čestice ograničava na manje područje prostora istraživanja, tj. omogućavamo lokalno pretraživanje.

Na slici 5.1 prikazana je pozicija čestice i ažuriranje vektora brzine na prethodno opisan način u dvodimenzionalnom prostoru. Isto tako je vidljivo da će ažurirani položaj čestice zavisiti ne samo od najboljih pozicija roja i čestice, nego i od veličine konfiguracijskih parametara.

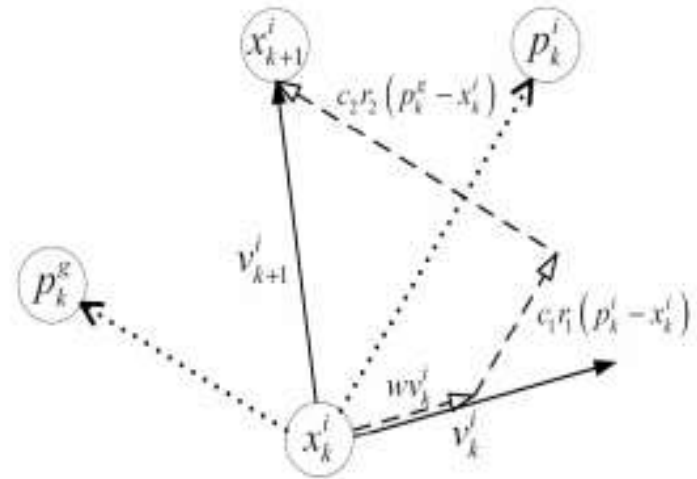

Slika 5.1: Pomeranje položaja čestice $i$ ažuriranje vektora brzine [3]

\section{EKSPERIMENTALNA ISTRAŽIVANJA}

Eksperimentalna istraživanja, objašnjena u ovom radu, bazirana su na doktorskoj disertaciji B. Savkovića [4]. Istraživanja su sprovedena na Fakultetu tehničkih nauka, u Laboratoriji za konvencionalne tehnologije obrade.

Tabela 6.1: Izmerene i računske vrednosti sa prosečnom

\begin{tabular}{|c|c|c|c|}
\hline \multirow{2}{*}{ R. br. } & \multicolumn{2}{|c|}{ Rezultati za Ra $[\mu \mathrm{m}]$ : } & \multirow{2}{*}{$\begin{array}{c}\text { Greška } \\
\text { eksperimenta }\end{array}$} \\
\hline & Eksperimentalni & Računski & \\
\hline 1 & 1,074 & 1,052 & $2 \%$ \\
\hline 2 & 1,081 & 1,117 & $4 \%$ \\
\hline 3 & 1,743 & 1,840 & $10 \%$ \\
\hline 4 & 1,645 & 1,838 & $19 \%$ \\
\hline 5 & 1,058 & 0,929 & $13 \%$ \\
\hline 6 & 1,023 & 0,951 & $7 \%$ \\
\hline 7 & 1,898 & 1,804 & $9 \%$ \\
\hline 8 & 1,734 & 1,738 & $0,4 \%$ \\
\hline 9 & 1,214 & 1,203 & $1 \%$ \\
\hline 10 & 1,236 & 1,203 & $3 \%$ \\
\hline 11 & 1,227 & 1,203 & $2 \%$ \\
\hline 12 & 1,175 & 1,203 & $3 \%$ \\
\hline 13 & 1,132 & 1,122 & $1 \%$ \\
\hline 14 & 1,253 & 1,146 & $11 \%$ \\
\hline 15 & 0,999 & 1,123 & $12 \%$ \\
\hline 16 & 2,556 & 3,617 & $30 \%$ \\
\hline 17 & 1,245 & 1,336 & $9 \%$ \\
\hline 18 & 1,237 & 1,118 & $12 \%$ \\
\hline 19 & 1,134 & 1,122 & $1 \%$ \\
\hline 20 & 1,235 & 1,146 & $9 \%$ \\
\hline 21 & 0,991 & 1,123 & $13 \%$ \\
\hline 22 & 2,489 & 3,617 & $31 \%$ \\
\hline 23 & 1,239 & 1,336 & $10 \%$ \\
\hline 24 & 1,221 & 1,118 & $10 \%$ \\
\hline & & sečna gr & $9 \%$ \\
\hline
\end{tabular}
greškom eksperimenta [7]

Modelovanje procesa obrade glodanjem izvedeno je na osnovu višefaktornog plana eksperimenta. Rezultati dobijeni eksperimentalnim ispitivanjem prikazani su $\mathrm{u}$ tabeli 6.1.

Obradom podataka dobijen je trofaktorni model drugog reda za srednju aritmetičku hrapavost obrađene površine:

$$
R_{a}=C v^{p_{1}} S_{1}{ }^{p_{2}} a^{p_{3}} *
$$




$$
* \exp \left[\begin{array}{c}
p_{11}(\ln v)^{2}+p_{22}\left(\ln s_{1}\right)^{2}+p_{33}(\ln a)^{2}+ \\
p_{12} \ln v \ln s_{1}+p_{13} \ln v \ln a+p_{23} \ln s_{1} \ln a
\end{array}\right]
$$

gde $v, s_{1}$ i $a$ predstavljaju režime obrade, $v$ - brzina rezanja $[\mathrm{m} / \mathrm{s}], s_{1}-$ pomak alata po zubu $[\mathrm{mm} / \mathrm{z}], a-$ dubina rezanja $[\mathrm{mm}]$. Ostale vrednosti predstavljaju konstantu C i eksponente (p1, p2, p3, p11, p22, p33, p12, p13, p23)

\section{OPTIMIZACIJA PROCESA OBRADE GLODANJEM}

Optimizacija procesa čeonog glodanja, odnosno određivanje optimalnih vrednosti režima obrade, sprovedena je primenom različitih prirodom-inspirisanih algoritama. U tu svrhu su korišćene tri jednokriterijumske metode: Optimizacija pomoću mravljeg algoritma, Optimizacija rojevima čestica i Genetski algoritam.

Funkcija cilja u sva tri slučaja je bila minimalna vrednost srednje aritmetičke hrapavosti $R_{a}$, odnosno $\left(R_{a}\right)_{\min }$.

Sam proces optimizacije je sproveden u programskom paketu MATLAB. ovaj softver ima brojne module, koji omogućavaju izvršavanje skrip koda za svaku od pobrojanih optimizacionih metoda.

Granične vrednosti ulaznih parametara (režima obrade) predstavljene su tabelom 6.2.

Tabela 6.2: Prikaz graničnih vrednosti ulaznih parametara

\begin{tabular}{|c|c|c|}
\hline Naziv parametra & $\begin{array}{c}\text { Minimalna } \\
\text { vrednost }\end{array}$ & $\begin{array}{c}\text { Maksimalna } \\
\text { vrednost }\end{array}$ \\
\hline$v[\mathrm{~m} / \mathrm{s}]$ & 2,356 & 5,864 \\
\hline$s_{1}[\mathrm{~mm} / \mathrm{z}]$ & 0,089 & 0,223 \\
\hline$a[\mathrm{~mm}]$ & 0,5 & 2,6 \\
\hline
\end{tabular}

\section{Analiza dobijenih rešenja}

Rezultati dobijeni pomoću različitih optimizacionih tehnika su predstavljeni u tabeli 6.3. Optimalne vrednosti dobijene pomoću različitih prirodom-inspirisanih algoritama (ACO, PSO i GA) se u potpunosti podudaraju. Ova činjenica pokazuje da je proces optimizacije obrade čeonim glodanjem sprovedena kvalitetno. Na kraju su optimalne vrednosti upoređene sa jednom klasičnom metodom optimizacije procesa obrade, Taguči metod.

Tabela 6.3: Optimalne vrednosti ulaznih parametara pri procesu čeonog glodanja

\begin{tabular}{|c|c|c|c|c|c|}
\hline \multirow{2}{*}{$\begin{array}{c}\text { Metoda } \\
\text { optimizaclje }\end{array}$} & \multicolumn{5}{|c|}{ OPTIMALNI PARAMETRI REZANjA } \\
\hline & \multicolumn{2}{|c|}{$\begin{array}{c}\text { Zahtevana izlazma } \\
\text { performansa procesa }\end{array}$} & \multirow{2}{*}{$\frac{\boldsymbol{v}[\boldsymbol{m} / \mathbf{s}\}}{2,36}$} & \multirow{2}{*}{$\frac{s_{1}|\mathbf{m m} / \mathbf{z}|}{0,1011}$} & \multirow{2}{*}{$\frac{\mathbf{a} \mid \mathbf{m} \mathbf{m}\}}{2,6}$} \\
\hline ACO & $R_{\mathrm{a}}\lceil\dot{\mu m}\rceil$ & 0,8236 & & & \\
\hline PSO & $R_{a}\lceil\mid m m\rceil$ & 0,8236 & 2,36 & 0,1011 & 2,6 \\
\hline GA & $R_{a}[u m]$ & 0,8236 & 2,36 & 0,1011 & 2,6 \\
\hline $\begin{array}{l}\text { Taguéci } \\
\text { metod }\end{array}$ & $R_{a}[\mu \mathrm{m}]$ & 0,875 & 2,35 & 0,089 & 2,6 \\
\hline
\end{tabular}

\section{ZAKLJUČAK}

$\mathrm{Na}$ osnovu cilja istraživanja, koji predstavlja ispitivanje mogućnosti efikasne primene ovih metoda (algoritama) u optimizaciji procesa obrade rezanjem sa određenom funkcijom cilja $\left(R_{a}\right)_{\min }$ i eksperimenata koji su izvršeni, može se zaključiti sledeće:
- potrebno je prethodno eksperimentalno istraživanje kako bi se formirao matematički model,

- bez kvalitetnog i pouzdanog matematičkog modela ne mogu se očekivati kvalitetna optimizaciona rešenja,

- da bi se izvršila optimizacija pomoću mravljeg algoritma, potrebno je uvesti kaznene faktore, koji omogućavaju ograničenje prostora pretrage, što nije slučaj za PSO,

- potreba za skript kodom određene metode (algoritma),

- brzina pronalaženja optimalnih rešenja bolja kod PSO metode (u odnosu na ACO),

- vreme pronalaska rešenja je neizvesno, ali je zagarantovano.

Postignuti rezultati, dobijeni pomoću različitih metoda (algoritama ACO, PSO i GA), navode na zaključak da su sve tri navedene metode prikladne i veoma pouzdane metode za optimizaciju parametara čeonog glodanja.

\section{LITERATURA}

[1] Dorigo M., Birattari M., Stützle T.: „Ant Colony Optimization: Artificial Ants as a Computational Intelligence Technique“, IRIDIA - Technical Report Series, September 2006.

[2] Reynolds C.: „Boids“, 1986. Homepage: https://www.red3d.com/cwr/boids/2.10.2018.

[3] Li J. G., Yao Y. X., Gao D., Liu C. Q., Yuan Z. J.: "Cutting parameters optimization by using particle swarm optimization (PSO)", Applied Mechanics and Materials, Vol. 10-12, 2008., pp. 879-883.

[4] Savković B.: "Doktorska disertacija: Modeliranje funkcije obradivosti pri procesu obrade glodanjem", Univerzitet u Novom Sadu, Fakultet tehničkih nauka, 2015.

[5] Sekulić M., Pejić V., Brezocnik M., Gostimirović M. Hadžistević M.: "Prediction of surface roughness in the ball-end milling process using response surface methodology, genetic algorithms, and grey wolf optimizer algorithm", Advances in Production Engineering \& Management, Vol. 13 (1), 2018., pp. 18-30.

\section{Kratka biografija:}

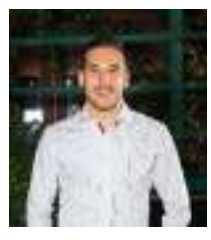

Anđelko Aleksić rođen je u Sremskoj Mitrovici 1994. god. Master rad na Fakultetu tehničkih nauka iz oblasti procesa obrade skidanjem materijala odbranio je 2018 . god.

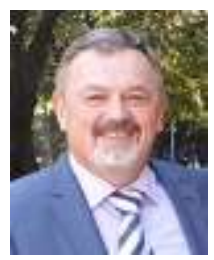

Milenko Sekulić rođen je u Prijepolju 1966. Doktorirao je na Fakultetu tehničkih nauka 2007. god., a od 2017. je zvanju redovnog profesora. Uža naučna oblast su procesi obrade skidanjem materijala. 